\title{
TEN YEAR INDEX
}

\section{History}

of

\section{Education}

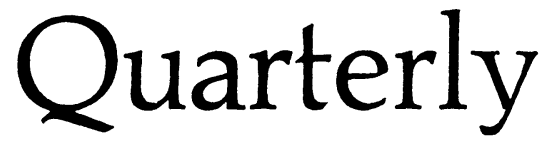

Vols. I-X, 1961-1970

\section{By}

\section{MURRAY S. SHERESHEWSKY}

\section{$\$ 5.00$}

All orders to be sent to: History of Education Quarterly, School of Education, New York University, 737 East Bldg., Washington Sq., New York, New York, 10003. This reference work does not replace an issue of the Journal and thus must be ordered independent of the regular subscription. 
